\title{
PRESENTACIÓN: "LOS ESTUDIOS ICONOGRÁFICOS EN ESPAÑA E IBEROAMÉRICA: UN ESTADO DE LA CUESTIÓN"
}

\author{
FRANCISCO JAVIER PIZARRO GÓMEZ \\ JOSÉ JULIO GARCÍA ARRANZ \\ Universidad de Extremadura
}

Los estudios de iconografía constituyen una disciplina que ha experimentado un extraordinario desarrollo durante las últimas décadas en el ámbito hispánico, siendo en la actualidad una línea de docencia/investigación amplia y sólidamente asentada, reconocida y muy fructífera en el área de las Humanidades. Ello es consecuencia, sin duda, del entusiasmo y del intenso trabajo llevado a cabo por varias generaciones de investigadores y equipos de trabajo en este periodo; pero responde, de igual modo, a la singular capacidad de adaptación de esta especialidad a las distintas posibilidades metodológicas y operativas que las nuevas tecnologías nos están brindando desde finales del siglo pasado.

Suele considerarse el punto de partida de la particular historiografía iconográfica en España la publicación del libro La mitología en el arte español del Renacimiento, obra de Diego Angulo Íñiguez que vio la luz en el año 1952. Sin embargo, muy posiblemente la primera aportación verdaderamente influyente en este terreno fuera la monografía de Julián Gállego Visión y símbolos en la pintura española del Siglo de Oro, editada inicialmente en francés en 1968 y traducida al español en 1984. Y es que la etapa crucial para la futura evolución de este tipo de estudios va a ser precisamente la década de los años ochenta, periodo en el que el infatigable catedrático Santiago Sebastián López, figura verdaderamente patriarcal e inspiradora para muchos de nosotros, fuera desgranando sucesivos trabajos en los ámbitos de la iconografía y la emblemática, centrados tanto en España como en Iberoamérica, que constituyen el fundamento de cuanto ha venido haciéndose después. Pero su aportación no quedó tan solo en su amplia y diversificada producción: fue director de la revista Traza y Baza: Cuadernos Hispanos 
de Simbología, Arte y Literatura, la primera de nuestro ámbito académico en dar prioridad a la línea iconográfica, y supo al mismo tiempo incentivar y formar desde su función docente a una serie de especialistas (varios de los cuales firman trabajos incluidos en el presente dossier) que implantaron los estudios de iconografia desde sus diversos enfoques y ámbitos de interés en diferentes universidades españolas y portuguesas. De este modo, la influencia del maestro "don Santiago", tanto directa como indirecta, ha resultado sustancial para el desarrollo de los estudios de esta especialidad en la Historia del Arte hispana, labor de "siembra" que germinará durante la década siguiente.

Desde finales de los ochenta asistiremos, en efecto, a importantes avances en la investigación vinculada a la iconografía y/o iconología en España. Junto a un interés creciente por parte de una nueva generación de estudiosos hacia estos enfoques, se observa un incremento progresivo del rigor metodológico en las publicaciones, sumado a un proceso de internacionalización de las mismas gracias a factores como el progresivo contacto con estudiosos e instituciones foráneas, no solo del ámbito iberoamericano, sino también anglosajón, a la traducción castellana de repertorios y obras de referencia en este campo difícilmente accesibles hasta aquellos momentos (Alianza Editorial, por ejemplo, nos fue descubriendo poco a poco a Panofsky, Gombrich, Saxl..., al tiempo que Akal y Tuero nos ofrecían traducciones y ediciones críticas de tratados y libros de emblemas fundamentales), y a la progresiva implantación de los primeros navegadores de Internet, que abrían ante el iconógrafo unas posibilidades de rastreo y una accesibilidad a las fuentes insospechadas hasta aquel momento. Por otra parte asistimos en esta etapa, como necesaria respuesta a las limitaciones que el trabajo individual ofrece frente a las enormes posibilidades que se estaban entonces abriendo en este campo, a la puesta en marcha de los primeros proyectos colectivos de investigación que, con el correr del tiempo y de las convocatorias, conllevaron la creación de equipos de trabajo especializados, cada vez más amplios y que, con la adecuada coordinación, han permitido abordar empresas cada vez más ambiciosas. Los Coloquios de Iconografía de la Fundación Universitaria Española y los congresos bianuales de la Sociedad Española de Emblemática en España, o los Coloquios de Emblemática en torno a Filippo Picinelli del Colegio de Michoacán, en México, permitieron sin duda fomentar el contacto entre investigadores y facilitar este tipo de colaboraciones interuniversitarias o internacionales, sin olvidar la incidencia que tendrán las actas y publicaciones surgidas de estos encuentros. Hito culminante en este proceso fue la creación en Vitoria-Gasteiz del Instituto de Estudios Iconográficos Ephialte, que comenzó su andadura en 1989 bajo la dirección de Jesús María González de Zárate, y que, con sus imponentes biblioteca, gabinete de estampas 
y fototeca, sus congresos periódicos y sus publicaciones -incluyendo la revista Lecturas de Historia del Arte- fue durante varios años epicentro en nuestro país de la investigación y difusión de este tipo de estudios. Muy pronto, además, los proyectos en marcha irán adquiriendo un carácter cada vez más multidisciplinar, sobre todo en aquellos ámbitos del amplio espectro de la iconografía en los que existe una clara interacción con la literatura o los estudios clásicos, como es el caso de la Emblemática o las relaciones festivas. La complejidad de estos ámbitos icónico-textuales y la necesidad de enfoques integrales e interdisciplinares que los nuevos tiempos exigen, requieren del concurso de especialistas de muy distintas áreas de conocimiento -filólogos e historiadores del arte, de la literatura o de la cultura-, a los que muy pronto se incorporarán los técnicos informáticos una vez que se toma conciencia de que, gracias a los vertiginosos avances en la capacidad de los ordenadores y mejora de los programas digitales, la creación de bases de datos interrelacionales o bibliotecas digitales se van erigiendo, en paralelo a las colecciones o series editoriales en papel, en un procedimiento fundamental para organizar, analizar y difundir los resultados de las investigaciones. Se rompe por fin la barrera que venía existiendo entre los ámbitos humanísticos y técnicos, y se abandonan viejos prejuicios, dando inicio a lo que más adelante se denominarán Humanidades digitales.

Debe reseñarse aquí que, en el contexto del referido carácter multidisciplinar que los estudios de iconografía van adquiriendo desde finales del siglo pasado, algunos de los más importantes instrumentos de apoyo a los mismos, como veremos en el presente monográfico, han sido creados por iniciativas surgidas desde el ámbito de la Filología o la Historia de la Literatura, y que oscilan entre la publicación de colecciones en volúmenes impresos -como sucede con la edición de Mundus Symbolicus de Filippo Picinelli, sustentado por el Colegio de Michoacán en Zamora, México- o las bases de datos que sobre libros de emblemas o divisas históricas, entre otros temas, ofrece la Biblioteca Digital Siglo de Oro (BIDISO) de la Universidade da Coruña. Pero, además de todo lo anterior, con el tránsito al nuevo milenio asistimos a un interés cada vez mayor por el rigor y precisión en las cuestiones metodológicas y terminológicas, necesarios en un ámbito de estudios que hasta entonces pecaba en muchas ocasiones de falta de sistematización, fomentándose una actitud que contribuirá al necesario rigor académico y científico de sus aportaciones. Resulta significativa en este sentido la aparición de ensayos como los de Manuel Antonio Castiñeiras (Introducción al método iconográfico, publicado en 1997, y ampliado en 1998), o los dos volúmenes de la Iconografia e iconología de Rafael García Mahíques (que ven la luz, respectivamente, en 2008 y 2009), en especial, en este caso, la segunda entrega: "Cuestiones de método". 
Con tales fundamentos críticos, metodológicos y técnicos, a partir de la rica experiencia adquirida durante aquellos años, estamos asistiendo durante el último cuarto de siglo a una auténtica edad de oro en los estudios de iconografía. Nos encontramos ante un panorama ibérico e iberoamericano rico y complejo, con grupos de trabajo firmemente establecidos y muy activos, diversas publicaciones periódicas especializadas (a los Cuadernos de Arte e Iconografia de la FUE se han ido incorporando otras como Imago, Potestas, De Medio Aevo, Eikon Imago...), proyectos de larga duración y gran alcance en marcha y un número creciente de congresos, jornadas y talleres dedicados en exclusiva a esta disciplina. Es esta situación la que nos ha llevado a proponer como apartado monográfico del presente número de Norba. Revista de Arte una serie de trabajos en los que se pusieran de manifiesto el propósito, objetivos, desarrollo y principales logros de algunas de las principales iniciativas que se están llevando a cabo en el ámbito de la iconografía en España e Iberoamérica, contemplada esta desde su sentido más amplio, ante la amplia diversidad de posibilidades que se nos ofrecen en la actualidad. Hemos reunido contribuciones que den a conocer planteamientos de interés tanto de carácter personal como fruto de grupos de investigación muy afianzados y con una extensa trayectoria, pero sin perder de vista los que atiendan al principio de transversalidad, con proyectos surgidos desde ámbitos diversos como la historia del arte, la historia de la literatura o la filología clásica; hemos querido contemplar, al mismo tiempo, líneas de trabajo cuyos resultados estén destinados esencialmente a la creación de colecciones o series de volúmenes impresos junto a otros que se sustentaran en páginas web y bibliotecas digitales como principal medio de difusión de sus resultados; hemos incluido, en fin, propuestas con décadas de desarrollo a sus espaldas que aún permanecen vigentes y otras que están ahora poniéndose en marcha. El objetivo es, como resulta evidente, dejar constancia de la diversidad y relevancia que la disciplina iconográfica ha alcanzado en el momento presente $\mathrm{y}$, sobre todo, de su potencial de proyección futura, a través de contribuciones que traten de cubrir, en la medida de lo posible, el ámbito geográfico hispano/iberoamericano, o que, en algunos casos se propongan, como veremos, conectar conceptualmente ambas realidades físicas y culturales.

\section{- $\mathbf{O}-$}

El presente dossier contiene por una parte, como hemos indicado, artículos en los que se da detallada noticia de proyectos destinados prioritariamente a la creación de series impresas de publicaciones, concebidas como obra de 
referencia o consulta en determinados ámbitos de los estudios iconográficos, o como repertorios o instrumenta de apoyo para el desarrollo de futuras investigaciones. Dentro del ámbito de las propuestas individuales, hemos de encuadrar el proyecto llevado a cabo durante las tres últimas décadas por Fernando Moreno Cuadro en la Universidad de Córdoba acerca de visualidad de santa Teresa de Jesús, fundamentado en el rastreo, análisis y clasificación de los temas y tipos iconográficos relativos a la fundadora del Carmelo, que cuenta con un inmenso imaginario; los resultados han visto la luz recientemente en cuatro volúmenes, publicados anualmente entre 2016 y 2019, en los que se organizan, de manera sistemática y profusamente ilustrada, las distintas tipologías y vertientes de la imagen de la santa. En cuanto a las iniciativas de carácter colectivo, contamos con contribuciones relativas a tres de los más relevantes proyectos emprendidos en este campo en el ámbito hispánico, desarrollados desde hace años por grupos de investigación amplios y muy consolidados. Mencionemos, en primer lugar, el proyecto de traducción y edición de la gran enciclopedia de emblemas y empresas Mundus Symbolicus del abad Filippo Picinelli que se lleva a cabo en el Centro de Estudios de las Tradiciones de El Colegio de Michoacán (Zamora, México) desde 1987, con un equipo de trabajo formado por investigadores de distintas disciplinas y con amplios conocimientos en la traducción del latín, coordinado inicialmente por Eloy Gómez Bravo, y en la actualidad por Bárbara Skinfill Nogal. Sus resultados van a ver la luz a través de diecisiete tomos cuidadosamente editados que abarcan los veintitrés libros de la obra, de los cuales han han sido editados hasta el momento nueve volúmenes, estando otros ocho en distintas fases de preparación, poniendo de este modo a nuestra disposición un manual básico de enorme repercusión. Por su parte, Los tipos iconográficos de la tradición cristiana es una iniciativa que se orienta como una historia diacrónica de los tipos iconográficos cristianos planteada desde la Historia universal de las imágenes, puesto en marcha en 2001 y llevado a cabo por el grupo de investigación APES. Estudis de cultura visual, en la Universitat de València, bajo la coordinación de Rafael García Mahíques. El trabajo, en el que colabora un equipo interuniversitario con larga experiencia en estos estudios, se está traduciendo en un monumental programa editorial de veintiséis volúmenes, que cuenta ya con cinco publicados y otros tres en diversas fases de elaboración. Se trata de una colección que responde a un planteamiento de trabajo riguroso y sistemático, y que está llamada a suplir la ausencia histórica de obras de referencia de estas características en el ámbito de habla hispana. En tercer lugar, no podía faltar una aportación referida a uno de los apartados de los estudios iconográficos más destacables y prolíficos en nuestro ámbito cultural como como es el de la fiesta y sus manifestaciones efímeras interés que se intensificó a partir de trabajos como Fiesta, poder y arquitectura 
de Antonio Bonet Correa, publicado en 1990-, a través de una aproximación al proyecto Triunfos Barrocos, auténtico "buque insignia" del grupo de investigación Iconografía e Historia del Arte (IHA) de la Universitat Jaume I, en Castellón. Puesto en marcha en 2009 bajo la dirección de Víctor Mínguez, esta iniciativa se propone localizar, clasificar, analizar y editar las manifestaciones gráficas del arte festivo barroco en todos los territorios que formaron parte de la Monarquía Hispánica durante la Edad Moderna, como se especifica en el texto firmado por el propio Mínguez e Inmaculada Rodríguez Moya. Con esta finalidad, a partir de 2010, ya han sido publicados seis volúmenes de los doce previstos (alguno de ellos cuenta con versión EBook), más un séptimo volumen recopilatorio, obras cuya calidad y primorosa edición han sido objeto de diversos reconocimientos.

Otro bloque de artículos está formado por aquellos que dan a conocer proyectos plenamente insertos en la esfera de las Humanidades digitales, cuyos resultados se exponen sustancialmente en bases de datos o bibliotecas digitales libremente accesibles a través de la red. Algunos de ellos, que pueden considerarse verdaderos pioneros en este sentido, cuentan ya con un largo desarrollo diacrónico y con equipos de trabajo muy afianzados, lo que se traduce en unos resultados disponibles ya desde hace algún tiempo. Así, el Proyecto para el estudio de las fuentes grabadas del arte colonial (PESSCA por sus siglas en inglés), es una base de datos accesible a través de una página web, creada y gestionada por Almerindo Ojeda (UC Davis College of Letters and Science, California, EE. UU.), lanzada en el año 2005. Destinada a documentar el impacto que tuvieron los grabados, mayoritariamente europeos, sobre el arte colonial americano, cuenta en la actualidad con más de 5000 identificaciones o correspondencias entre ambos tipos de manifestaciones, habiéndose convertido en un referente en los estudios de arte colonial; pero, como se indica en el artículo, a la ingente labor de catalogación y hermenéutica que supone esta aplicación, se suma su potencial como recurso documental para la restauración y recuperación del arte colonial. En segundo lugar, la Biblioteca Digital Ovidiana es otra destacada iniciativa, coordinada por Fátima Díez Platas, de la Universidade de Santiago de Compostela, al frente de un amplio equipo multidisciplinar, cuyo principal propósito es la localización, estudio y digitalización de los ejemplares relativos a obras ilustradas del poeta latino Publio Ovidio Nasón, y en especial sus Metamorfosis. La investigación se está llevando a cabo en las bibliotecas españolas con fondo antiguo, creando un sitio web operativo desde 2012 especializado en la obra ovidiana como herramienta digital que posibilita el rápido acceso del investigador a los libros ilustrados y sus correspondientes imágenes publicados entre los siglos XV y XIX. Por su parte, Symbola es una 
nueva base de datos de acceso gratuito integrada, junto a otros recursos, en la Biblioteca Digital Siglo de Oro (BIDISO), creada por el grupo de investigación SIELAE-Grupo Hispania, de la Universidade da Coruña, colectivo creado a mediados de los años noventa, bajo la coordinación sucesiva de Sagrario López Poza y Nieves Pena Sueiro, ambas firmantes del artículo que aquí presentamos. La plataforma está destinada a recopilar el mayor número posible de divisas o empresas históricas creadas entre los siglos XIV y XVII, tanto en el ámbito español como internacional. Operativa en línea desde 2017, ha conseguido revitalizar los estudios relativos a esta importante vertiente de la cultura simbólica medieval y moderna como es la emblemática personal.

Finalizamos la sección monográfica con la presentación de propuestas de futuro inmediato en este campo: se trata de proyectos que se encuentran en los primeros pasos de su andadura y que están destinados, como algunos de los referidos anteriormente, a la creación de bases de datos accesibles a través de las correspondientes páginas web, acompañadas o no, según el caso, de la edición de material complementario en papel. Todas ellas tienen en común, además de constituir un testimonio más de la vitalidad que, como venimos comentando, disfrutan hoy los estudios de iconografía en el ámbito hispánico, el hecho de ofrecer un elocuente testimonio de la deriva de este tipo de iniciativas hacia el establecimiento, a través del análisis de los influjos visuales e iconográficos, de las conexiones culturales trazadas entre España y América en el mundo moderno y contemporáneo. Valga como ejemplo de ello el proyecto Orbis imagines: estampa y cultura visual en Andalucía y su impacto en el Nuevo Mundo (siglos XVI-XVIII) coordinado por Reyes Escalera Pérez, de la Universidad de Málaga, que se propone como doble objetivo el estudio de la estampa y su trascendencia en la cultura visual de Andalucía entre los siglos XVI y XVIII y la influencia en el arte del Nuevo Mundo de los grabados salidos de talleres andaluces. Cuenta para ello con un equipo interdisciplinar cuyo trabajo se expondrá a través de una base de datos que recogerán la información sobre las estampas recogidas, accesible a través de una web que se encuentra actualmente en construcción. El grupo de investigación "Extremadura y América" de la Universidad de Extremadura, coordinado por Francisco Javier Pizarro Gómez, presenta por su parte el proyecto Monumenta Iconográfica Americana: la imagen de América en las artes europeas e iberoamericanas; destinado a ofrecer un amplio banco de imágenes sobre la iconografía de la imagen de América en los tiempos de la modernidad y la contemporaneidad, herramienta susceptible de ser utilizada para diferentes campos académicos y productivos. Como indican las autoras del texto -Yolanda Fernández Muñoz y Alicia Díaz Mayordomo-, la difusión de la página web se combinará con publicaciones complementarias 
y la edición de una revista digital anual. Y finalizamos esta panorámica con sendas iniciativas propuestas y coordinadas por Pedro Germano Leal (John Carter Brown University Library, Providence, EE. UU.). La primera de ellas, el proyecto Global Emblems, tiene como objetivo fundamental, con la colaboración de un equipo internacional de especialistas y el apoyo de la Society for Emblem Studies, mapear, documentar y estudiar la presencia de emblemas aplicados como componente significativo en la cultura material del ámbito occidental y vincular estos conjuntos con las colecciones digitales preexistentes de libros de emblemas en diversos sitios web especializados. El segundo de los proyectos, Transmission and Intermediality: the impact of the emblematic culture in Ibero-America, analizará los datos obtenidos de la anterior base de datos con el fin de llegar a comprender el papel de los emblemas en el proceso colonial en las Américas y sus implicaciones ideológicas, políticas y sociológicas en la modernidad temprana.

Esperamos poder ofrecer al lector interesado, a través de esta serie de contribuciones, una ilustrativa y suficientemente representativa foto fija del estado de la cuestión de los estudios de iconografía en España e Iberoamérica, testimonio, ya lo hemos dicho, del buen estado de salud de que goza la disciplina en el momento actual. Agradecemos muy encarecidamente a los autores de los textos sus excelentes aportaciones, muy en especial si tenemos en cuenta que han sido elaboradas en un período y bajo unas condiciones que no ha resultado fáciles por las estrictas limitaciones y condicionantes que en diversos aspectos de la actividad académica nos ha supuesto la pandemia del COVID-19 durante este año 2020.

Francisco Javier Pizarro Gómez

Universidad de Extremadura Catedrático de Historia del Arte https://orcid.org/0000-0003-4588-1449

jpizarro@unex.es

José Julio García Arranz

Universidad de Extremadura Profesor Titular de Historia del Arte https://orcid.org/0000-0002-7052-8754

turko@unex.es 